\title{
Phytochemical, Antioxidant and Toxicological Investigation of Morinda citrifolia L. Blossoms
}

\author{
Shixin Deng, Brett J. West, 'Afa K. Palu, and C. Jarakae Jensen \\ Research and Development Department, Tahitian Noni International, 737 East, 1180 South, American Fork, UT 84003, USA \\ Correspondence should be addressed to Shixin Deng, shixin_deng@tni.com
}

Received 18 August 2011; Accepted 26 September 2011

Academic Editors: H. Dorman, T. Fossen, and M. L. Villarreal

Copyright () 2012 Shixin Deng et al. This is an open access article distributed under the Creative Commons Attribution License, which permits unrestricted use, distribution, and reproduction in any medium, provided the original work is properly cited.

Noni blossoms have a long history of medicinal uses in tropical areas. This study was conducted to investigate the major phytochemical components, toxicological properties, and antioxidant activity of noni blossoms. An HPLC-PDA method was developed and validated for the identification and quantification of major components. The major phytochemicals were iridoid glycosides, deacetylasperulosidic acid and asperulosidic acid, and flavonoids, quercetin-3-O- $\alpha$-L-rhamnopyranosyl- $(1 \rightarrow 6)-\beta$-Dglucopyranoside and kaempferol-3-O- $\alpha$-L-rhamnopyranosyl- $(1 \rightarrow 6)-\beta$-D-glucopyranoside, each present at 3.764, 3.576, 1.513, and $3.096 \mathrm{mg} / \mathrm{g}$, respectively. The aqueous extract of noni blossoms, at $500 \mu \mathrm{g} / \mathrm{mL}$, exhibited greater antioxidant activity in the 2,2diphenylpicrylhydrazyl radical scavenging assay than green tea $(88.11 \pm 0.01 \%$ versus $76.60 \pm 0.05 \%)$. A primary DNA damage test in E. coli PQ37 (SOS-chromotest) and a twenty-four hour brine shrimp toxicity test did not reveal any genotoxic or cytotoxic activity. These results provide a useful reference for the identification of noni blossoms as well as preliminary evaluation of safety and efficacy. Further evaluation of the potential applications of noni blossoms is warranted.

\section{Introduction}

Morinda citrifolia L. (Rubiaceae), commonly known as noni, is indigenous to tropical regions, such as French Polynesia, Tonga, Hawaii, Australia, and other islands of the Pacific. The fruit and leaf of the noni tree have long been used in traditional medicine for the improvement of various conditions, including arthritis, colds, diabetes, inflammation, and pain $[1,2]$. The fruit and leaf have been studied extensively in the past decade [3-5]. Noni blossoms have not drawn much attention from modern researchers even though ethnobotanical studies report a similarly long history of medicinal use. Indigenous people used noni blossoms in preparing native medicines [6], which were applied topically to treat conjunctivitis, styes, abscesses, irritated or red eyes, sore eyes, and so forth [7]. Juice pressed from the blossoms was also used alone for the treatment of sore eyes [8]. Young blossoms were employed to relieve pains after childbirth [9]. The blossoms were also eaten to treat kidney and bladder disorders [10]. Noni blossoms were described as "flowers form in globose heads, each head about 1 inch long and bearing many flowers. Each flower consists of white, tubular, 5-7-lobed corolla, about 1/3 inch long. Flowers closely packed, in various stages of development; those near apex, still green buds while older flowers, near base have opened or have already closed" by Krauss [11]. Among the limited references, noni blossoms were found to contain glucosides, anthraquinones, and flavonoids $[12,13]$. There is very little information on the phytochemical components or pharmacological and toxicological activities of noni blossom in modern scientific literature. As such, this paper aims to provide an extensive investigation on the phytochemicals in noni blossoms as well as an initial assessment of safety and antioxidant activity.

\section{Materials and Methods}

2.1. Reagents and Materials. HPLC grade acetonitrile $(\mathrm{MeCN})$, methanol $(\mathrm{MeOH})$, water $\left(\mathrm{H}_{2} \mathrm{O}\right)$, and 2,2-Diphenylpicrylhydrazyl (DPPH) were obtained from Sigma-Aldrich (St. Louis, MO, USA). Analytical grade formic acid was purchased from Spectrum Chemical Manufacturing Corp. (New Brunswick, NJ, USA). The chemical standards deacetylasperulosidic acid (1), asperulosidic acid (2), 
quercetin-3-O- $\alpha$-L-rhamnopyranosyl-( $1 \rightarrow 6)-\beta$-D-glucopyranoside (3), and kaempferol-3-O- $\alpha$-L-rhamnopyranosyl$(1 \rightarrow 6)$ - $\beta$-D-glucopyranoside $(4)$ were isolated from noni fruits in our laboratory. Their identification and purities were determined by HPLC, MS-ESI, and NMR to be higher than $99 \%$. Noni blossom was collected from Tahiti and dried naturally. Voucher specimens of noni blossom are deposited in our lab.

2.2. HPLC Instrumentation Conditions. Chromatographic separation was performed on a Waters 2690 separations module coupled with 996 PDA detectors and equipped with an Atlantis C18 column $(4.6 \mathrm{~mm} \times 250 \mathrm{~mm} ; 5 \mu \mathrm{m}$, Waters Corporation, Milford, MA, USA). The pump was connected to two mobile phases: $\mathrm{MeCN}$, and $0.1 \%$ formic acid in $\mathrm{H}_{2} \mathrm{O}$ $(\mathrm{v} / \mathrm{v})$ and eluted at a flow rate of $0.8 \mathrm{~mL} / \mathrm{min}$. The mobile phase was programmed consecutively in linear gradients as follows: $0-5 \mathrm{~min}, 0 \% \mathrm{~A}$ and $45 \mathrm{~min}, 30 \% \mathrm{~A}$. The PDA detector was monitored in the range of 210-400 $\mathrm{nm}$ (235 and $365 \mathrm{~nm}$ were selected for quantitative analysis of $\mathbf{1 - 2}$ and 3-4, resp.). The injection volume was $10 \mu \mathrm{L}$ for each of the sample solutions. The column temperature was maintained at $25^{\circ} \mathrm{C}$. Data collection and integration were performed using Waters Millennium software revision 32.

2.3. Preparation of Standard and Sample Solutions. Standards 1-4 were accurately weighed and then dissolved in an appropriate volume of $\mathrm{MeOH}$ to produce corresponding stock solutions. The working standard solutions for the calibration curve were prepared by diluting the stock solution with $\mathrm{MeOH}$, producing five concentrations. All stock and working solutions were maintained at $0^{\circ} \mathrm{C}$ in a refrigerator. The calibration curves of standards were plotted after linear regression of the peak areas versus concentrations.

The extraction of phytochemicals from the dried noni blossom was optimized by using three different methods as shown in Table 1. In each experiment, $50 \mathrm{~mL}$ of $\mathrm{MeOH}$, $\mathrm{MeOH}-\mathrm{H}_{2} \mathrm{O}(1: 1)$, or $\mathrm{MeOH}-\mathrm{EtOH}(1: 1)$ was added into $1 \mathrm{~g}$ of sample, respectively, and sonicated for $60 \mathrm{~min}$ with and without heating. The solutions were then filtered and prepared into $20 \mathrm{mg} / \mathrm{mL}$ for HPLC analysis. All sample solutions were filtered through a nylon microfilter $(0.45 \mu \mathrm{m}$ pore size) before the HPLC experiments.

2.4. Analytical Method Validation. Characterization of phytochemicals in the noni blossom was conducted by comparing their HPLC retention times and UV maximum absorptions with those of standards isolated in our previous experiments. The working solutions of standards were diluted sequentially to determine the limits of detection (LOD) and quantitation (LOQ), which were defined as the lowest concentrations of analytes that can be detected and quantified on the basis of signal-to-noise ratios $(S / N)$ of $3: 1$ and $10: 1$, respectively. In the study, intra- and interday precisions of the HPLC method were measured by triplicate injections of samples on 5 consecutive days. Accuracy of the method was assessed by the recovery percentage of analytes in the spiked samples. The recovery percentage was calculated using the ratio of concentration detected to those spiked. Variation was evaluated by the relative standard deviation (RSD) of triplicate injections in the HPLC experiments.

\subsection{2,2-Diphenylpicrylhydrazyl (DPPH) Radical Scavenging} Assay. For the DPPH test, an aqueous extract was prepared by steeping $1 \mathrm{~g}$ dried blossom in $100 \mathrm{~mL}$ hot water $\left(100^{\circ} \mathrm{C}\right)$ for 10 minutes, and then filtered. Next, $1 \mathrm{~mL}$ of the aqueous extract was diluted to $10 \mathrm{~mL}$ with deionized water to a solids concentration of $500 \mu \mathrm{g} / \mathrm{mL}$. The diluted sample, and a water blank, was combined $1: 1(\mathrm{v} / \mathrm{v})$ with $0.4 \mathrm{mM}$ DPPH in ethanol. The absorbance of each sample and blank was read at $515 \mathrm{~nm}$ after incubation at $37^{\circ} \mathrm{C}$ for $1 \mathrm{hr}$. Percent radical scavenging activity was calculated by dividing the absorbance difference between the blank and sample by the absorbance of the blank alone. Green tea aqueous extract, prepared in the same manner as the blossom, served as a positive control. The differences in DPPH radical scavenging activities were assessed using Student's $t$-test.

2.6. Primary DNA Damage Test in E. coli PQ37 (SOSChromotest). The SOS-chromotest in E. coli PQ37 was used to determine the potential for noni blossom to induce primary DNA damage. This test was carried out according to the previously developed method [14]. E. coli $\mathrm{PQ} 37$ was incubated at $37^{\circ} \mathrm{C}$ in the presence of replicate samples of an ethanol extract of dried noni blossoms solids up to $5000 \mu \mathrm{g} \mathrm{mL}^{-1}$ in a 96-well plate. Following incubation with the samples, 5-bromo-4-chloro-3-indolyl$\beta$-D-galactopyranoside was added to the wells to detect $\beta$-galactosidase enzyme activity, which is induced during SOS repair of damaged DNA. Nitrophenyl phosphate is also added to the wells to measure alkaline phosphatase activity, an indicator of cell viability. The samples were again incubated, and the absorbance of the samples, blanks, and controls was measured at 410 and $620 \mathrm{~nm}$ with a microplate reader. Vehicle blanks and positive controls, $5 \mu \mathrm{g} \mathrm{mL}^{-1} 4$ nitroquinoline 1-oxide (4NQO), were included in this test. The induction factor of each material was calculated by dividing the absorbance of the sample at $620 \mathrm{~nm}$ by that of the blank, while also correcting for cell viability. Induction factors less than two indicate an absence of genotoxic activity.

2.7. Twenty-Four Hour Brine Shrimp Toxicity Test. The 24hour brine shrimp toxicity test has been used for more than 20 years for the assessment of the cytotoxicity of plant materials [15]. Replicate samples of the aqueous extract were prepared in $3 \% \mathrm{NaCl}, \mathrm{pH} 8$, to a concentration of $1 \mathrm{mg} \mathrm{mL}^{-1}$. A green tea aqueous extract was prepared in the same manner to serve as a well-known food control. Brine shrimp (Artemia salina) eggs were hatched in salt water $3 \%$ $\mathrm{NaCl}$ ), and nauplii were transferred to vials containing $15 \mathrm{~mL}$ of test solution. These were incubated for $24 \mathrm{hr}$ at room temperature. Following incubation, the numbers of active nauplii were counted and mean percent survival calculated for both aqueous extracts, with corresponding standard deviations. In this test, as well as in the primary DNA damage test, comparisons were made with Student's $t$-test. 
TABLE 1: The contents of major phytochemicals in noni blossom determined by different extraction methods.

\begin{tabular}{|c|c|c|c|c|c|c|}
\hline \multirow{2}{*}{ Method } & \multicolumn{2}{|c|}{ Extraction } & \multicolumn{4}{|c|}{ Contents of phytochemicals ${ }^{\mathrm{a}, \mathrm{b}}(\mathrm{mg} / \mathrm{g})$} \\
\hline & Solvent & Heat & 1 & 2 & 3 & 4 \\
\hline 1 & $\mathrm{MeOH}$ & on & $3.764 \pm 0.009$ & $3.576 \pm 0.024$ & $1.513 \pm .009$ & $3.096 \pm .008$ \\
\hline 2 & $\mathrm{MeOH}: \mathrm{H}_{2} \mathrm{O}(1: 1)$ & on & $3.256 \pm 0.014$ & $2.903 \pm 0057$ & $1.448 \pm 0.017$ & $2.590 \pm 0.016$ \\
\hline 3 & $\mathrm{MeOH}: \mathrm{EtOH}(1: 1)$ & off & $0.880 \pm 0.040$ & $0.421 \pm 0.021$ & $0.880 \pm 0.040$ & $0.421 \pm 0.021$ \\
\hline
\end{tabular}

${ }^{a}$ Data represent the mean \pm SD of triplicate determination. ${ }^{b}$ Phytochemicals $\mathbf{1}-\mathbf{4}$ represent deacetylasperulosidic acid, asperulosidic acid, quercetin-3-O- $\alpha$ L-rhamnopyranosyl- $(1 \rightarrow 6)$ - $\beta$-D-glucopyranoside, and kaempferol-3-O- $\alpha$-L-rhamnopyranosyl- $(1 \rightarrow 6)-\beta$-D-glucopyranoside, respectively.

TABLE 2: Chromatographic and analytical characteristics of the phytochemical constituents in noni blossom.

\begin{tabular}{lccccc}
\hline Analyte $^{\mathrm{a}}$ & Linearity range $(\mathrm{mg} / \mathrm{mL})$ & Calibration equation $^{\mathrm{b}}$ & LOD $(\mu \mathrm{g} / \mathrm{mL})$ & LOQ $(\mu \mathrm{g} / \mathrm{mL})$ & Correlation coefficient \\
\hline $\mathbf{1}$ & $0.0017-1.74$ & $y=1.443 \times 10^{7} x+17342$ & 10.60 & 34.80 & 0.9994 \\
$\mathbf{2}$ & $0.0016-0.80$ & $y=1.537 \times 10^{7} x+40805$ & 9.70 & 32.00 & 0.9999 \\
$\mathbf{3}$ & $0.0010-0.10$ & $y=2.028 \times 10^{7} x-460$ & 0.03 & 0.10 & 0.9995 \\
$\mathbf{4}$ & $0.0010-0.10$ & $y=1.651 \times 10^{7} x+5299$ & 0.01 & 0.04 & 0.9998 \\
\hline
\end{tabular}

a 1-deacetylasperulosidic acid; 2-asperulosidic acid 3-quercetin-3-O- $\alpha$-L-rhamnopyranosyl-( $1 \rightarrow 6)-\beta$-D-glucopyranoside; 4-kaempferol-3-O- $\alpha$-L-rhamnopyranosyl- $(1 \rightarrow 6)-\beta$-D-glucopyranoside. ${ }^{b}$ Five data points $(n=3), x=$ concentration of compounds $(\mathrm{mg} / \mathrm{mL}), y=$ peak area.

\section{Results and Discussion}

3.1. Quantitative Determination of Major Phytochemicals. A preliminary experiment on the contents of iridoids in noni blossom was investigated previously [16]. To further quantitatively determine the major phytochemical constituents in the noni blossoms, an analytical HPLC-PDA method was established and validated in this experiment. The experiments first investigated extraction methods involving different solvents with and without heating, as shown in Table 1. The experimental results indicate that heating has a significant effect on the extraction efficacy of phytochemical compounds in the noni blossom. Extraction performed with $\mathrm{MeOH}$ in a heated sonicator resulted in the detection of the highest concentrations of each phytochemical. The HPLC chromatographic method was validated with the noni blossom samples to determine LOD, LOQ, linearity, intraday and interday precisions, and accuracy (Tables 24). Good linearity (correlation coefficients $=0.9994-0.9998$ ) was observed for phytochemicals 1-4, within the range of concentrations investigated. The intra- and interday precisions for 1-4 over five consecutive days, shown as RSD's, were from $0.14 \%$ to $1.07 \%$, indicating good repeatability and stability of the compounds. Recoveries of analytes 14 were from $92.47 \%$ to $96.10 \%$, with RSD's less than $1 \%$ (Table 4).

Four major phytochemical compounds in the noni blossom were identified as iridoids, deacetylasperulosidic acid (1) and asperulosidic acid (2), and flavonoids, quercetin-3-O- $\alpha$-L-rhamnopyranosyl- $(1 \rightarrow 6)-\beta$-D-glucopyranoside (3) and kaempferol-3-O- $\alpha$-L-rhamnopyranosyl$(1 \rightarrow 6)$ - $\beta$-D-glucopyranoside (4) (Figure 1). A typical HPLC chromatogram of the noni blossom is shown in Figure 2. The chromatographic peaks marked $\mathbf{1 - 4}$ in the HPLC profiles of the samples exhibited consistency on UV absorptions and LC retention time to those of standards 1-4.

The contents of 1-4 in the noni blossom were further investigated using the validated HPLC method. The analytical results showed that the amounts of $\mathbf{1}$ and $\mathbf{2}$ in the

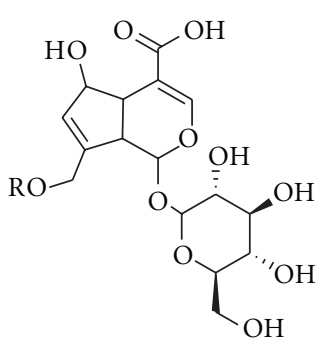

$1: \mathrm{R}=\mathrm{H}$

2: $\mathrm{R}=\mathrm{CH}_{3} \mathrm{CO}$

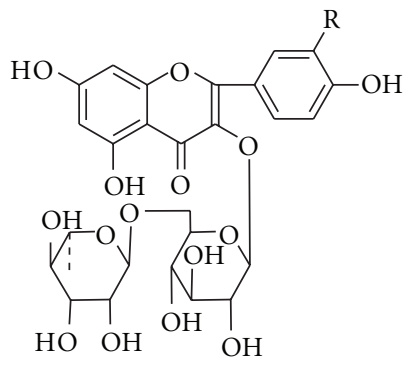

3: $\mathrm{R}=\mathrm{OH}$

4: $\mathrm{R}=\mathrm{H}$
FIGURE 1: Chemical structures of major phytochemicals in noni blossoms (1-deacetylasperulosidic acid; 2 -asperulosidic acid; 3quercetin-3-O- $\alpha$-L-rhamnopyranosyl- $(1 \rightarrow 6)$ - $\beta$-D-glucopyranoside; 4-kaempferol-3-O- $\alpha$-L-rhamnopyranosyl- $(1 \rightarrow 6)-\beta$-D-glucopyranoside).

noni blossoms are $3.764 \mathrm{mg} / \mathrm{g}$ and $3.576 \mathrm{mg} / \mathrm{g}$, respectively, while the contents of 3 and 4 are $1.513 \mathrm{mg} / \mathrm{g}$ and $3.096 \mathrm{mg} / \mathrm{g}$, respectively (Table 1).

3.2. Antioxidant Activity. The DPPH radical scavenging activity (mean \pm standard deviation) of noni blossom aqueous extract was $88.11 \pm 0.01 \%$, which as greater than green tea at $76.60 \pm 0.05 \%(P<0.001)$, at a concentration of $500 \mu \mathrm{g} / \mathrm{mL}$. The increased capacity for noni blossoms to scavenge the DPPH radical, as compared to green tea, suggests notable antioxidant activity and potential applications in commercial food products.

3.3. Primary DNA Damage Test in E. coli PQ37 (SOSChromotest). In the SOS-chromotest (Table 5), the ethanol extract of noni blossoms did not cause any significant induction of SOS repair at any concentration. The SOSchromotest results have a high level of agreement $(86 \%)$ with 
TABLE 3: Intra- and interday precisions and stability assays for the quantitative determination of phytochemicals in noni blossom by HPLCPDA.

\begin{tabular}{lcccccccc}
\hline \multirow{2}{*}{ Analyte $^{\mathrm{a}}$} & \multicolumn{2}{c}{ Day 1 } & \multicolumn{2}{c}{ Day 3 } & \multicolumn{2}{c}{ Day 5 } & \multicolumn{3}{c}{ Interday } \\
& Abs $^{\mathrm{b}}$ & RSD $^{\mathrm{c}}(\%)$ & Abs $^{\mathrm{b}}$ & $\mathrm{RSD}^{\mathrm{c}}(\%)$ & Abs $^{\mathrm{b}}$ & RSD $^{\mathrm{c}}(\%)$ & Abs $^{\mathrm{b}}$ & RSD $^{\mathrm{c}}(\%)$ \\
\hline $\mathbf{1}$ & 1068731 & 0.24 & 1080281 & 0.23 & 1079968 & 0.36 & 1076326 \\
$\mathbf{2}$ & 1058266 & 0.72 & 1069847 & 0.14 & 1068083 & 0.48 & 1065399 \\
$\mathbf{3}$ & 435712 & 0.57 & 446015 & 0.24 & 441476 & 0.33 & 441067 & 0.67 \\
$\mathbf{4}$ & 855226 & 0.29 & 865931 & 0.49 & 864005 & 0.54 & 861721 & 0.69 \\
\hline
\end{tabular}

${ }^{a}$ 1-deacetylasperulosidic acid, 2 -asperulosidic acid, 3-quercetin-3- $O$ - $\alpha$-L-rhamnopyranosyl- $(1 \rightarrow 6)-\beta$-D-glucopyranoside, 4-kaempferol-3-O- $\alpha$-L-rhamnopyranosyl- $(1 \rightarrow 6)-\beta$-D-glucopyranoside; ${ }^{b}$ absorption peak areas; ${ }^{\mathrm{c}}$ Relative standard deviation; $n=3$.

TABlE 4: Accuracy assays for the quantitative determination of major phytochemicals in noni blossom by HPLC-PDA.

\begin{tabular}{lccc}
\hline Analyte $^{\mathrm{a}}$ & $\begin{array}{c}\text { spiked } \\
(\mathrm{mg} / \mathrm{mL})\end{array}$ & Recovery $^{\mathrm{b}}(\%)$ & RSD $(\%)$ \\
\hline $\mathbf{1}$ & 2.75 & $96.10 \pm 0.21$ & 0.22 \\
$\mathbf{2}$ & 2.60 & $95.28 \pm 0.44$ & 0.47 \\
$\mathbf{3}$ & 0.85 & $92.47 \pm 0.20$ & 0.22 \\
$\mathbf{4}$ & 2.00 & $93.65 \pm 0.49$ & 0.53 \\
\hline
\end{tabular}

1-deacetylasperulosidic acid, 2-asperulosidic acid, 3-quercetin-3-O- $\alpha$ L-rhamnopyranosyl- $(1 \rightarrow 6)-\beta$-D-glucopyranoside, 4-kaempferol-3-O- $\alpha$-Lrhamnopyranosyl- $(1 \rightarrow 6)$ - $\beta$-D-glucopyranoside; ${ }^{\mathrm{b}}$ Mean $\pm \mathrm{SD}, n=3$.

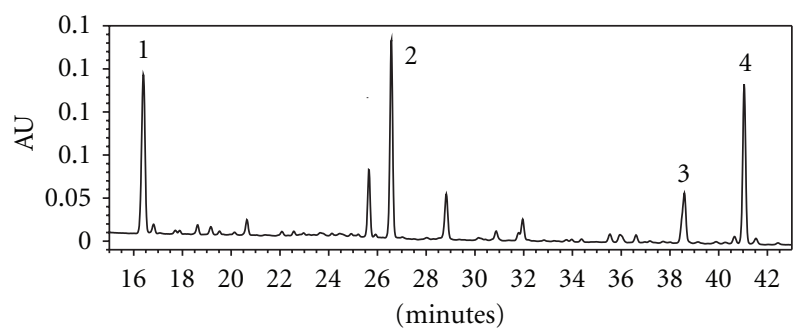

FIgURE 2: HPLC Chromatographic profiles of phytochemicals in noni blossoms (1-deacetylasperulosidic acid; 2 -asperulosidic acid; 3-quercetin-3-O- $\alpha$-L-rhamnopyranosyl- $(1 \rightarrow 6)-\beta$-D-glucopyranoside; 4-kaempferol-3-O- $\alpha$-L-rhamnopyranosyl- $(1 \rightarrow 6)-\beta$-D-glucopyranoside).

those from the reverse mutation assay or Ames test [17]. Therefore, the SOS-chromotest has some utility in predicting potential mutagenicity in addition to primary DNA damage. These results suggest a lack of genotoxic activity in noni blossoms.

3.4. Twenty-Four Hour Brine Shrimp Toxicity Test. The brine shrimp nauplii survival rate (mean \pm standard deviation) after 24-hour incubation in noni blossom aqueous extract was $76.13 \pm 10.05 \%$, indicating a lack of cytotoxic potential $\left(\mathrm{LC}_{50}>1 \mathrm{mg} \mathrm{mL}^{-1}\right)$. Comparatively, the survival rate in green tea aqueous extract was $56.63 \pm 16.71 \%$.

\section{Conclusions}

The study investigated major phytochemical constituents in noni blossoms. Two iridoids, deacetylasperulosidic acid
TAble 5: Primary DNA damage test (SOS-chromotest) of noni blossom.

\begin{tabular}{lcc}
\hline Sample & $\begin{array}{c}\text { Dose } \\
\left(\mu \mathrm{g} \mathrm{mL}^{-1}\right)\end{array}$ & Induction factors \\
\hline Noni blossom & 5000 & $1.29 \pm 0.12$ \\
1600 & $1.18 \pm 0.04$ \\
500 & $1.05 \pm 0.01$ \\
160 & $0.91 \pm 0.01$ \\
50 & $0.96 \pm 0.08$ \\
& 16 & $0.97 \pm 0.04$ \\
4 NQO $^{\mathrm{b}}$ & 5 & $7.5 \pm 0.70^{*}$ \\
\hline
\end{tabular}

${ }^{\mathrm{a}}$ Mean $\pm \mathrm{SD}$; ${ }^{\mathrm{b}}$ Positive control; ${ }^{*} P<0.05$ compared to blank.

and asperulosidic acid, as well as two flavonoids, quercetin3 -O- $\alpha$-L-rhamnopyranosyl- $(1 \rightarrow 6)$ - $\beta$-D-glucopyranoside and kaempferol-3-O- $\alpha$-L-rhamnopyranosyl- $(1 \rightarrow 6)-\beta$-Dglucopyranoside, were quantitatively determined to be the major phytochemicals in the noni blossoms. The presence of these four phytochemicals may significantly contribute to the medicinal properties of noni blossoms. Together, these compounds may be used as markers for identification and authentication of noni blossom materials. The noni blossom was also found to possess significant antioxidant properties, with DPPH radical scavenging activity greater than green tea. Toxicological studies showed no cytotoxic and genotoxic effects from noni blossoms. The current findings warrant further evaluation of the potential applications.

\section{References}

[1] W. McClatchey, "From Polynesian healers to health food stores: changing perspectives of Morinda citrifolia (Rubiaceae)," Integrative Cancer Therapies, vol. 1, no. 2, pp. 110-120, 2003.

[2] M. Y. Wang, B. J. West, C. J. Jensen et al., "Morinda citrifolia (noni): a literature review and recent advances in noni research," Acta Pharmacologica Sinica, vol. 23, no. 12, pp. 1127-1141, 2002.

[3] A. D. Pawlus and A. D. Kinghorn, "Review of the ethnobotany, chemistry, biological activity and safety of the botanical dietary supplement Morinda citrifolia (noni)," Journal of Pharmacy and Pharmacology, vol. 59, no. 12, pp. 1587-1609, 2007. 
[4] O. Potterat and M. Hamburger, "Morinda citrifolia (noni) fruit-phytochemistry, pharmacology, safety," Planta Medica, vol. 73, no. 3, pp. 191-199, 2007.

[5] S. Deng, A. K. Palu, B. J. West, C. X. Su, B. N. Zhou, and J. C. Jensen, "Lipoxygenase inhibitory constituents of the fruits of noni (Morinda citrifolia) collected in Tahiti," Journal of Natural Products, vol. 70, no. 5, pp. 859-862, 2007.

[6] T. G. Yuncker, The Flora of Niue Island, Bernice P. Bishop Museum Bulletin 178, Published by the Museum, Honolulu, Hawaii, USA, 1943, Reprinted by Kraus Reprint, New York, NY, USA, 1974.

[7] A. Dittmar, "Morinda citrifolia L.-use in indigenous Samoan medicine," Journal of Herbs, Spices \& Medicinal Plants, vol. 1, no. 3, pp. 77-92, 1993.

[8] E. Christophersen, Flowering Plants of Samoa, Bernice P. Bishop Museum Bulletin 128, Published by the Museum, Honolulu, Hawaii, USA, 1935, Reprinted by Kraus Reprint, New York, NY, USA, 1971.

[9] S. F. Glassman, The Flora of Ponape, Bernice P. Bishop Museum Bulletin 209, Published by the Museum, Honolulu, Hawaii, USA, 1952, Reprinted by Kraus Reprint, New York, NY, USA, 1971.

[10] B. H. Krauss, "Medicine and medicinal herbs," in Plants in Hawaiian Culture, p. 103, University of Hawaii Press, Honolulu, Hawaii, USA, 1993.

[11] B. H. Krauss, Ethnobotany of Hawai'I, University of Hawaii Press, Honolulu, Hawaii, USA, 1976.

[12] J. Singh and R. D. Tiwari, "Flavone glycosides from the flowers of Morinda citrofolia," Journal of the Indian Chemical Society, vol. 53, no. 4, p. 424, 1976.

[13] T. D. Tiwari and J. Singh, "Structural study of the anthraquinone glycosides from the flowers of Morinda citrifolia," Journal of the Indian Chemical Society, vol. 54, no. 4, pp. 429-430, 1977.

[14] F. Fish, I. Lampert, A. Halachmi, G. Riesenfeld, and M. Herzberg, "The SOS chromotest kit: a rapid method for the detection of genotoxicity," Toxicity Assessment, vol. 2, no. 2, pp. 135-147, 1987.

[15] B. N. Meyer, N. R. Ferrigni, J. E. Putnam, L. B. Jacobsen, D. E. Nichols, and J. L. McLaughlin, "Brine shrimp: a convenient general bioassay for active plant constituents," Planta Medica, vol. 45 , no. 1, pp. 31-34, 1982.

[16] S. Deng, B. J. West, A. K. Palu, and C. J. Jensen, "Determination and comparative analysis of major iridoids in different parts and cultivation sources of Morinda citrifolia," Phytochemical Analysis, vol. 22, no. 1, pp. 26-30, 2011.

[17] R. Legault, C. Blaise, D. Rokosh, and R. Chong-Kit, "Comparative assessment of the SOS chromotest kit and the mutatox test with the Salmonella plate incorporation (Ames test) and fluctuation tests for screening genotoxic agents," Environmental Toxicology and Water Quality, vol. 9, no. 1, pp. 45-57, 1994. 


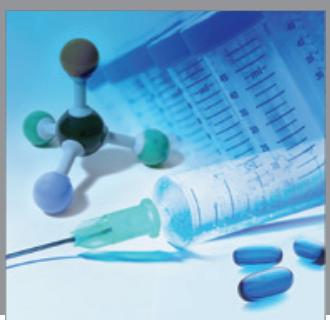

International Journal of

Medicinal Chemistry

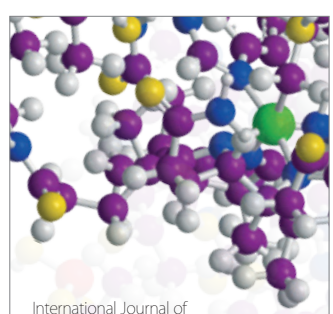

Carbohydrate Chemistry

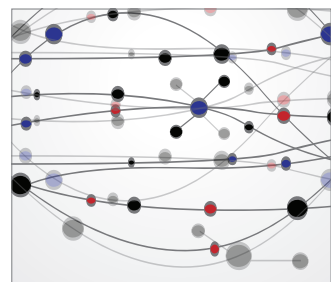

The Scientific World Journal
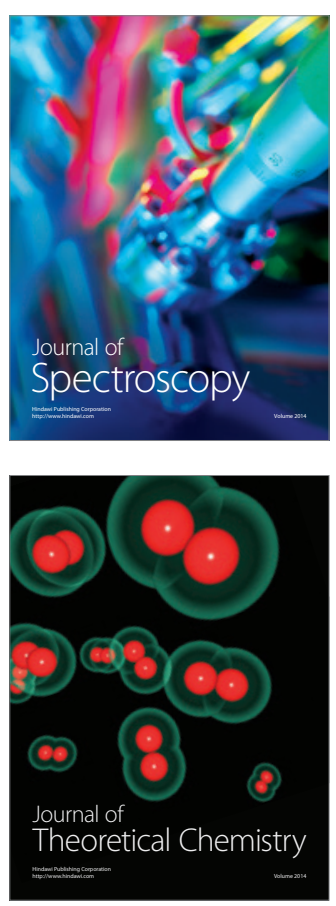
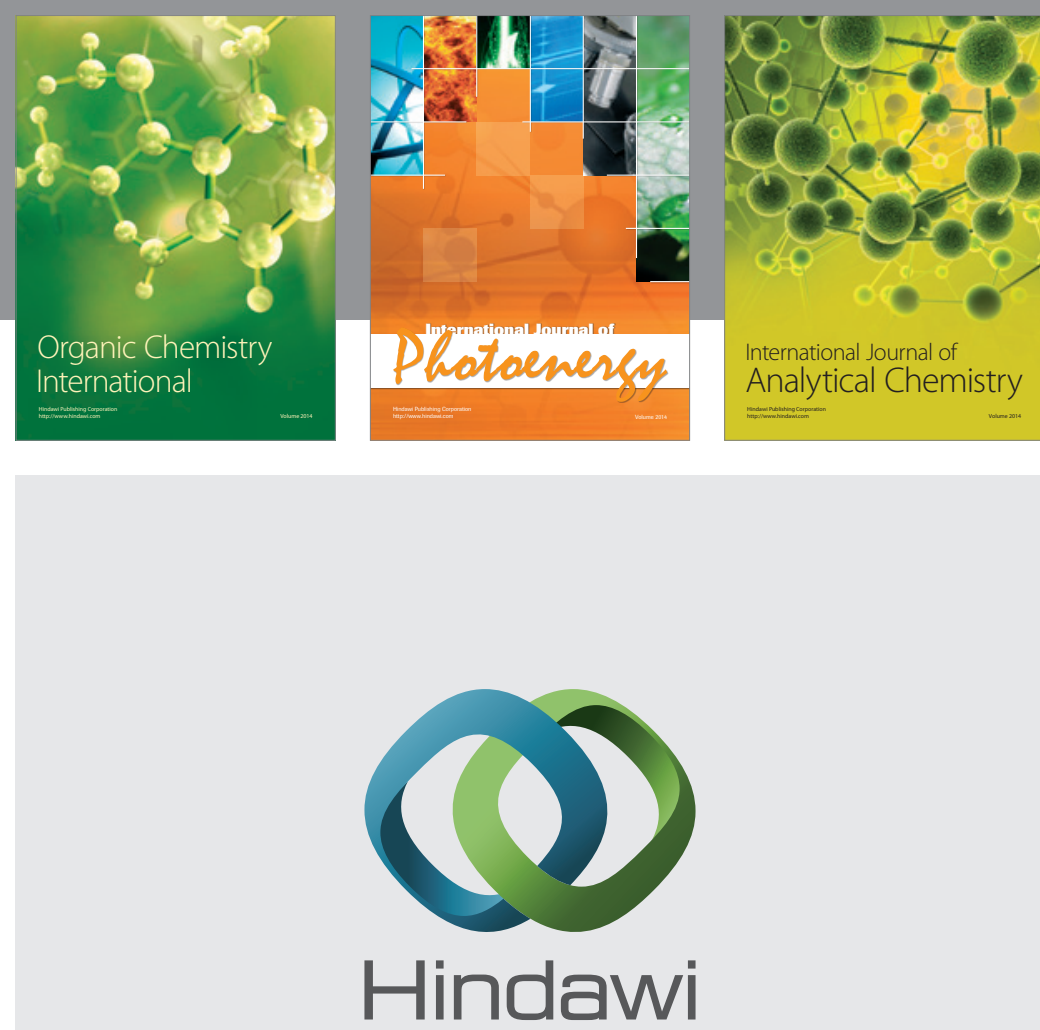

Submit your manuscripts at

http://www.hindawi.com
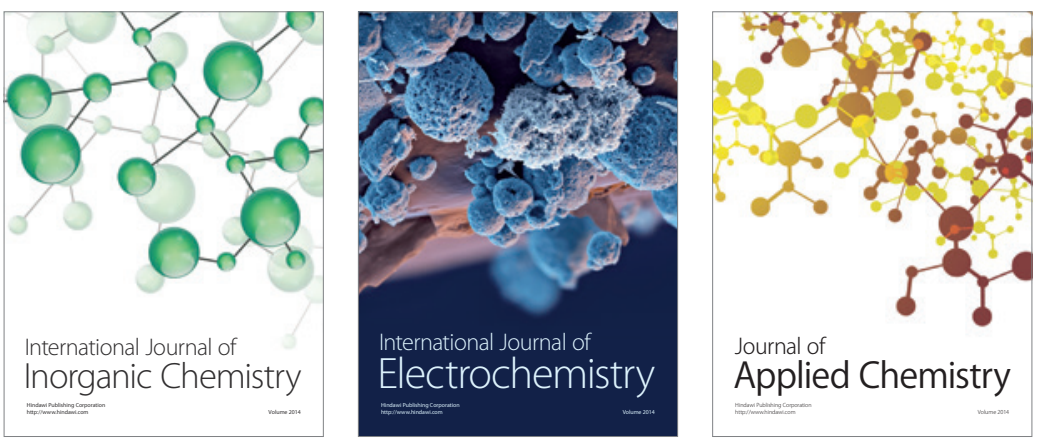

Journal of

Applied Chemistry
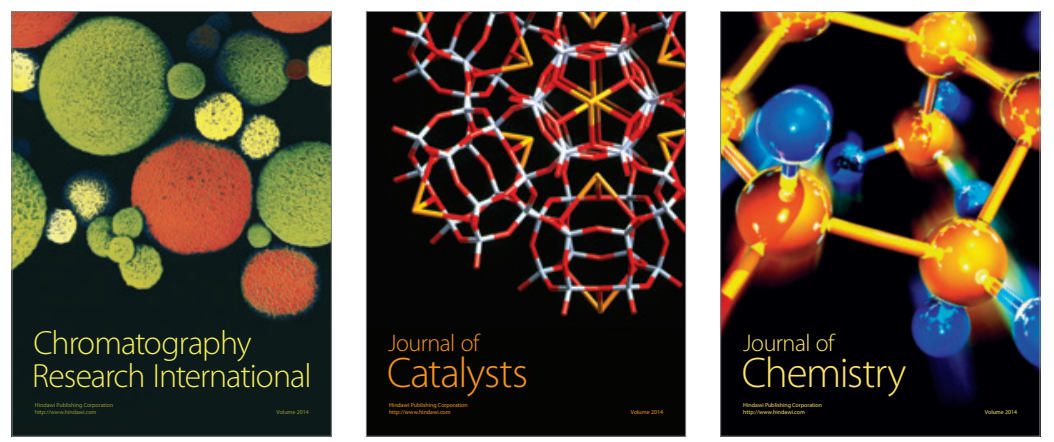
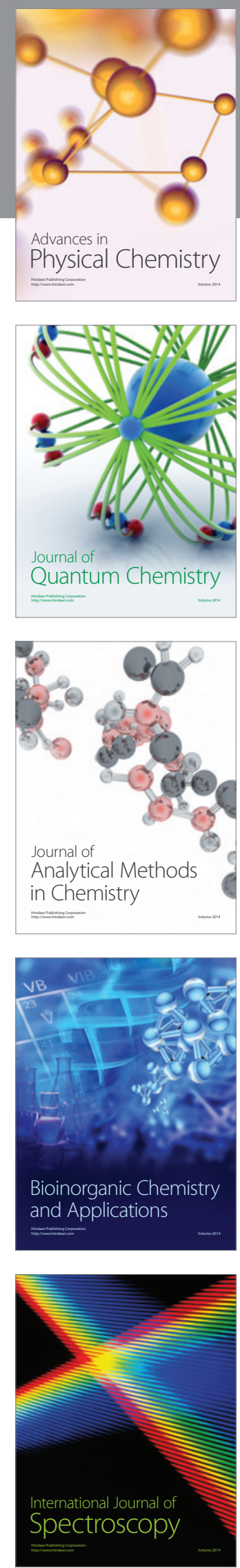